\title{
MEDIANERAS A BRASILEÑA: COMO CONSTRUIR E TRABALHAR RELAÇÕES INTERPESSOAIS EM CURSOS ONLINE DE ESPANHOL?
}

\author{
Medianeras a Brasileña: ¿Cómo construir y trabajar relaciones \\ interpersonales en cursos de Español Online?
}

\author{
Priscila RABANÉA \\ Universidade Federal do Paraná \\ priscila.rabanea@ufpr.br \\ https://orcid.org/0000-0001-8146-9553 \\ Milena dos SANTOS ARRUDA \\ Universidade Federal do Paraná \\ milena.arruda@ufpr.br \\ https://orcid.org/0000-0002-2375-4222 \\ Fernanda SILVA VELOSO \\ Universidade Federal do Paraná \\ fernandaveloso@ufpr.br \\ https://orcid.org/0000-0002-5263-6479
}

\begin{abstract}
RESUMO: Em "Medianeras: Buenos Aires na Era do Amor Virtual" (2011), o diretor Gustavo Taretto discute como a tecnologia e a internet afetam as relações interpessoais, podendo tanto nos aproximar quanto nos afastar. Embora o filme seja antigo, o contexto social de um mundo em quarentena, em que meramente sair de casa é pouco recomendado, torna seus questionamentos mais válidos do que nunca. Assim, não surpreende que a virtualização das relações sociais afete enormemente o ato de educar, levando aqueles não familiarizados com o ensino remoto a desbravarem esse território até então desconhecido e discuti-lo mais amplamente dentro da comunidade acadêmica. Por isso, nosso objetivo é apresentar como professores em formação, estagiários do projeto Formação de Idiomas para Vida Universitária (FIVU), responsáveis por elaborar e ministrar as aulas de um curso de Espanhol realizado entre junho e julho de 2020 na plataforma Microsoft Teams, buscaram contornar os desafios comunicativos provenientes do distanciamento espacial entre alunos e professores através da afetividade, do trabalho colaborativo e do debate e diálogo constantes. $\mathrm{Na}$ discussão baseada em nossas interações durante as aulas e em
\end{abstract}

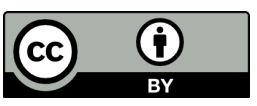


conversas com alunos por meio do WhatsApp, mostraremos como as estratégias adotadas influenciaram positivamente na experiência final. PALAVRAS-CHAVE: ensino remoto; relações interpessoais; afetividade.

RESUMEN: En Medianeras (2011), Gustavo Taretto discute la acción de la tecnología y de la internet sobre las relaciones interpersonales, capaces de aproximarnos o alejarnos los unos de los otros. Aunque la película sea antigua, el contexto social de un mundo en cuarentena haz con que sus cuestionamientos sean más valederos que nunca. Así, no sorprende a nadie que la virtualización de las relaciones sociales influya enormemente sobre la educación, llevando aquellos que todavía no están familiarizados con la enseñanza remota a explorar ese territorio desconocido y discutirlo más largamente dentro de la comunidad académica. Por ello, nuestro objetivo es explicar cómo los profesores en formación, pasantes del proyecto Formação de Idiomas para Vida Universitária (FIVU) - responsables por elaborar e impartir clases en un curso en línea de español que tuvo lugar entre junio y julio del 2020 en la plataforma Teams intentaron eludir los desafíos comunicativos provocados por el alejamiento espacial entre alumnos y profesores usando la afectividad, el trabajo en equipo y el debate y diálogo constantes. A través de discusiones basadas en nuestras interacciones durante las clases y en charlas con los alumnos por medio del WhatsApp, enseñaremos cómo las estrategias adoptadas impactaron positivamente en la experiencia final. PALABRAS CLAVE: enseñanza remota; relaciones interpersonales; afectividad.

Mensagens de texto. Uma nova linguagem adaptada para dez teclas que reduz uma das linguagens mais lindas, a um vocabulário primitivo, limitado e gutural. "O futuro está na fibra ótica" dizem os visionários. Do trabalho, você vai poder aumentar a temperatura da sua casa. Claro, ninguém vai esperar você com a casa quentinha. Bem-vinda à era das relações virtuais.

(Mariana, Medianeras, 2011)

\section{E O COTIDIANO NA ERA DAS RELAÇÕES (FORÇADAMENTE) VIRTUAIS}

O filme argentino Medianeras: Buenos Aires na Era do Amor Virtual (2011), dirigido por Gustavo Taretto, narra a história de personagens que vivem sós em Buenos Aires e tentam se libertar das amarras da solidão impostas pela cultura virtual. 
Assim como no filme, também acreditamos que as relações interpessoais podem ficar comprometidas no ensino online. Aproximar-se dos estudantes a ponto de instigá-los a estudar e a participar ativamente das aulas não presenciais é um desafio que muitos professores não precisariam enfrentar em sala de aula convencional.

No primeiro semestre de 2020, o mundo acompanhou chocado a descoberta da Covid- $19^{1}$ e suas muitas consequências ao redor do globo - dentre elas o isolamento social e a interrupção das aulas em escolas e universidades. Em março, pensávamos que essa crise seria passageira e que tudo estaria normalizado em três ou quatro meses. Infelizmente, a rápida propagação do vírus e a dificuldade em controlá-lo em território nacional provou que seria necessário mais tempo para tal, de modo que foi preciso pensar rapidamente em soluções para permitir o prosseguimento das atividades educacionais de alguma forma.

Com relação à Universidade Federal do Paraná (UFPR), muitos cursos se voltaram ao uso da plataforma Microsoft Teams como forma de retomar suas atividades - algo que foi alvo de críticas por parte daqueles que acreditam que esse movimento favorece uma precarização do ensino cujos efeitos não poderiam ser totalmente revertidos após o retorno das atividades presenciais. A resposta da UFPR aos críticos foi explicar que cursos de "DNA presencial" não seriam ministrados da mesma forma que os cursos que fazem parte do espectro do "Ensino a Distância" (EaD), mas sim considerando o que defende o chamado "Ensino Remoto Emergencial" (ERE), em que se propõe que os professores mantenham suas aulas o mais próximo possível do modo presencial dentro das limitações de espaço e tempo decorrentes da pandemia (BARRA; GOMES, 2020; HODGES et al., 2020).

Tendo em vista a impossibilidade de aulas presenciais no primeiro semestre de 2020, o projeto de extensão Formação em Idiomas para Vida Universitária (FIVU) ${ }^{2}$ optou por ministrar aulas de Espanhol Básico para alunos da pós-graduação que tivessem interesse em prestar provas de suficiência nessa língua. Para isso, um grupo de nove alunos das disciplinas de Prática de Docência em Línguas Estrangeiras Modernas

\footnotetext{
${ }^{1}$ Covid-19 é uma doença infecciosa causada pelo vírus SARS-CoV-2, popularmente conhecido como "coronavírus" ou "novo coronavírus".

${ }^{2}$ O FIVU é um projeto criado em 2009 com o intuito de proporcionar não apenas um espaço de formação para licenciandos em Letras, mas também permitir que a comunidade acadêmica (i.e., graduandos e pós-graduandos) tivesse acesso a cursos de língua estrangeira de qualidade e sem custos (N. A.).
}

Revista X, v. 16, n. 4, p. 1101-1119, 2021. 
Neolatinas I e II se disponibilizaram para participar da iniciativa na condição de professores-em-formação. ${ }^{3}$

Antes do início do CE-M1/20204, algumas reuniões foram marcadas para planejar a melhor maneira de ministrar as aulas. A primeira decisão a ser tomada foi a criação de um formulário para conhecer o perfil dos interessados. Com base na carga horária laboral e acadêmica ${ }^{5}$ desses alunos, foi decidido que ministraríamos um curso de seis horas semanais por turma - aulas obrigatórias de línguas às segundas e quartas para a turma $\mathrm{A}$ e às terças e quintas para a turma $\mathrm{B}$ e aulas culturais, opcionais, às sextas para ambas as turmas, uma vez que boa parte deles tinha aulas da pós às sextas no período da manhã. Além disso, seguindo o que pregam alguns defensores do ERE (cf. HODGES et al., 2020), optamos por aulas síncronas ministradas na plataforma Microsoft Teams das $9 \mathrm{~h} 30$ às $11 \mathrm{~h} 10$, com possibilidade de assistir às gravações das aulas posteriormente. Uma vez que foi decidido que o CE-M1/2020 teria oito semanas ${ }^{6}$, nos dividimos em três duplas e um trio, sendo cada grupo inteiramente responsável por duas semanas de aulas, isto é, montar uma unidade temática (UT) e convidar uma (ou mais) pessoa(s) falante(s) de espanhol como língua materna para participar dos encontros culturais.

Por exigência da coordenação, também foi necessário pensar em uma forma de avaliar os alunos. Por isso, foi decidido que, uma vez que seria possível avaliar em aula as dimensões da leitura, fala e escuta, as tarefas avaliativas semanais contariam também com textos a serem entregues toda semana pelos alunos — assim, poderíamos abarcar as quatro habilidades linguísticas.

Voltando ao título deste texto, medianeras é também o nome dado a paredes de muitos edifícios portenhos. Essas espécies de "muros cegos" são laterais e não permitem que janelas sejam instaladas. Assim como elas, as "paredes invisíveis" instaladas nos cursos à distância (ou remotos) não permitem que "janelas" sejam abertas e que haja $\mathrm{o}$ relacionamento interpessoal desejável entre professores e alunos. O impacto das

\footnotetext{
${ }^{3}$ Professores-em-formação ou professores-praticantes: alunos licenciandos de Letras em período de estágio; Professores formadores: os professores universitários que coordenam o projeto e os cursos e atividades ofertadas; alunos: alunos de graduação e pós-graduação, de áreas diversas que buscavam os cursos de idiomas do projeto.

${ }^{4}$ CE-M1/2020: Curso de Espanhol - Módulo 1/2020. Como na época em que estávamos trabalhando ainda não havia um padrão para denominar os cursos, cada equipe criava um nome e uma sigla, como EFA ou FFA.

${ }^{5}$ Muitos dos alunos que se inscreveram para as aulas de Espanhol ministradas pelo nosso grupo não apenas tinham as aulas da pós-graduação, mas também continuaram trabalhando de casa durante os últimos meses (N. A.).

${ }^{6}$ O CE-M1/2020 teve início em 1 de junho de 2020 e se encerrou em 24 de julho de 2020 (N. A.). Revista X, v. 16, n. 4, p. 1101-1119, 2021. 
tecnologias da informação e da comunicação (TICs) sobre as relações pessoais que se estabelecem no ensino remoto é algo que investigamos aqui.

Diante do exposto, nosso objetivo é discutir o diálogo entre alunos e professores ao longo do CE-M1/2020, assim como as relações afetivas que a partir dele foram estabelecidas. Para isso, apresentaremos trechos das aulas síncronas realizadas no Microsoft Teams, bem como trechos de diálogos entre professores e alunos estabelecidos por meio do WhatsApp, do e-mail e do Google Classroom. As respostas dadas pelos alunos no questionário respondido ao final do CE-M1/2020 também serão consideradas aqui ${ }^{7}$.

$\mathrm{Na}$ seção a seguir, discorreremos sobre a teoria que embasou a nossa análise para, na sequência, mostrarmos como as estratégias adotadas ao longo do CE-M1/2020 influenciaram positivamente a experiência com aulas online, tanto sob o ponto de vista dos discentes quanto dos regentes.

\section{OS LAÇOS AFETIVOS NA CIDADE VIRTUAL "DESCONTROLADA, IM- PERFEITA E IRREGULAR"}

A cidade de Buenos Aires, no filme Medianeras, é a responsável pela produção de vínculos afetivos entre seus personagens. $\mathrm{Na}$ "cidade" virtual do ensino remoto esse vínculo é tão necessário quanto na real, principalmente para garantir que os alunos não evadam do curso quando se depararem com as dificuldades impostas pela tecnologia.

$\mathrm{O}$ conceito de afetividade adotado aqui está relacionado à teoria psicogenética proposta pelo psicólogo e político francês Henri Wallon — que, embora esteja relacionada ao desenvolvimento do ser humano desde a infância até a maturidade, ajuda a entender também o desenvolvimento educacional do ser em seu papel de aluno (MAHONEY; ALMEIDA, 2005). Uma das principais razões para tal está na forma como Wallon considera o meio em sua teoria. Segundo ele,

O meio é um complemento indispensável ao ser vivo. Ele deverá corresponder a suas necessidades e suas aptidões sensório-motoras e, depois, psicomotoras. Não é menos verdadeiro que a sociedade coloca o homem em presença de novos meios, novas necessidades e novos recursos que aumentam possibilidades de evolução e diferenciação individual. (WALLON, 1975, p. 164-165 apud MAHONEY; ALMEIDA, 2005, p. 17).

\footnotetext{
${ }^{7}$ Coletamos outras impressões dos discentes ao longo das aulas ministradas, dado que todas elas foram gravadas com o consentimento de todos os envolvidos e revisitadas pelos docentes no momento de escrita deste texto. Vale frisar que foi garantido o anonimato aos alunos, a fim de deixá-los mais à vontade para fazer suas observações e críticas.
} 
Para nós, a consideração da influência do meio no desenvolvimento do ensinoaprendizagem é de suma importância, uma vez que não apenas estamos utilizando uma plataforma até então desconhecida pela maioria dos envolvidos, mas também o fazemos em uma época de certa desconfiança do homem com relação ao mundo exterior, o que pode afetar a todos das mais diversas maneiras. Outro ponto de interesse para nós é a ideia de um processo em que todos os agentes envolvidos são mutuamente afetados uns pelos outros, sendo o ensino e a aprendizagem dois lados de uma mesma unidade e, como tal, devendo ser analisados em conjunto (MAHONEY; ALMEIDA, 2005).

No entanto, o que nos levou a buscar mais sobre como a teoria walloniana poderia nos ajudar a montar um curso mais atraente e efetivo tem relação com o tipo de relacionamento aluno-professor que costumamos encontrar em nosso país, em especial em cursos de idiomas. A formação de laços afetivos sólidos entre alunos e professores tende a diminuir a evasão dos alunos, que seguem motivados a participar das aulas e, às vezes, até a considerá-las "o ponto alto" de suas semanas — algo visto como incomum e até indesejável em outras partes do mundo ${ }^{8}$. Essa "peculiaridade" também aparece na maneira como a afetividade na educação foi tratada por décadas. Para Ferreira e AciolyRégnier (2010, p. 25), a recência na discussão de sua importância estaria relacionada a uma "influência positivista", que faria com que esse fator fosse considerado "não científico" e "irrelevante" e, assim, provocaria sua marginalização.

Outro ponto que também abordam os autores é a questão da humanização no ambiente escolar, que, para eles, é um dos "fundamentos da razão formativa" (p. 23). Essa humanização está ligada à maneira que a equipe pedagógica vai lidar com a afetividade na formação dos alunos. A respeito disso, consideram que uma escola que tenha a capacidade de refletir sobre seu papel educativo almejando uma educação humanizada é considerada comprometida - comprometimento que nos rondou em todos os momentos em que preparávamos as aulas, os materiais e os encontros culturais para nossos alunos, uma vez que o ambiente virtual criou a preocupação em oferecer uma aula tão boa quanto seria presencialmente. Entretanto, como apontam Ferreira e AciolyRégnier (2010, p. 23), objetivar uma educação humanizada "implica novos desafios para educação e para escola".

Sobre essa característica do ERE, apresentam Bozkurt e Sharma (2020) que "a educação online é um processo complexo, que requer um planejamento cuidadoso" (p. 2),

\footnotetext{
${ }^{8}$ Em um de nossos encontros culturais, um professor espanhol que já trabalhou em países como Brasil, China, Hungria e Portugal falou um pouco sobre como a proximidade aluno-professor existente no Brasil o surpreendeu, tendo vindo de uma experiência completamente diferente na China (N. A.).
} 
e, dessa forma, torna possível "uma aprendizagem ecológica" (p. 2), na qual todos podem se desenvolver de forma sustentável. Entretanto essa forma sustentável de se desenvolver só será estabelecida a partir de como o aluno está envolvido no processo, já que

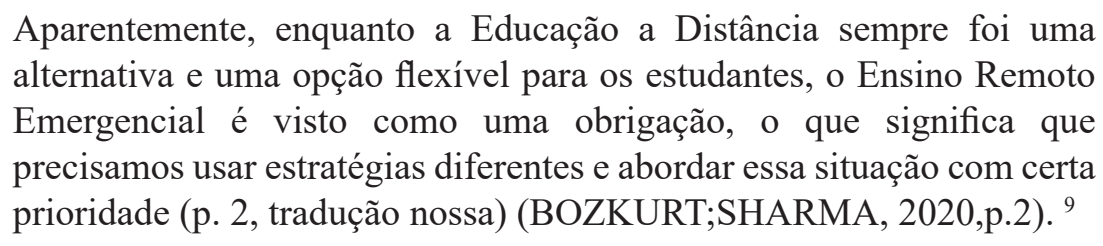

Dentre as estratégias sugeridas pelos autores citados está justamente a questão da comunicação. Embora os ambientes de comunicação virtuais sejam em alguma medida parecidos com aqueles presenciais, eles "dificultam o contacto gestual ou pessoal entre os utilizadores e caso não se tenha cuidado esses ambientes podem levar à criação de comunidades virtuais com falta de dimensão de carácter [...] e partilha de valores" (SOUSA, 2006, s. p.).

Segundo Moran (2000, p. 61), é preciso “chegar ao aluno por todos os caminhos possíveis: pela experiência, pela imagem, pelo som, pela representação (dramatizações, simulações), pela multimídia, pela interação on-line e off-line". Assim, é preciso que o(s) professor (es) façam uso de todas as mídias à disposição para esclarecer as dúvidas dos alunos ou para ajudá-los a superar dificuldades de cunho pedagógico ou técnico através da comunicação.

Dentre os caminhos possíveis citados por Moran (2000), aquele mais utilizado no CE-M1/2020 foi o do diálogo, que, para Freire (2005), é uma "exigência existencial". Foi por meio do uso da linguagem, do diálogo, que foi criado o vínculo entre alunos e professores e foi também por meio dela que foi despertado o interesse dos alunos para alguns tópicos trabalhados em sala de aula virtual.

\section{A DISTÂNCIA TRANSACIONAL NO MUNDO CONTEMPORÂNEO (IN)VI- SÍVEL}

Em Medianeras (2011), é bastante evidente que um dos protagonistas vive uma vida muito mais virtual que o outro. Martín, um web designer que também é um agorafóbico em recuperação, tende a começar suas relações interpessoais pela internet,

\footnotetext{
9 "Apparently, while distance education has always been an alternative and flexible option for learners, emergency remote teaching is an obligation, which means that we have to use different strategies and approach the case with different priorities." (BOZKURT; SHARMA, 2020, p. 2). 
fazendo "amigos" no Oriente Médio, que só aparecem para pedir dinheiro, e se envolvendo com mulheres que conhece buscando alguém para passear com sua cadela ou em sites de relacionamento. No entanto, ao encontrar algumas dessas pessoas cara a cara, ele fala pouco e age de maneira um tanto desajeitada, fazendo com que essas interações resultem em frustração para todos os envolvidos. Um dos poucos momentos em que Martín mantém um diálogo sincero com alguém via internet é quando, casualmente, conhece Mariana em um chat e tenta ensiná-la a se relacionar virtualmente. Embora essa interação também acabe de modo frustrante, não é pelo conteúdo da conversa (da qual ambos desfrutavam), mas por um fator externo: a luz acaba quando estão prestes a trocar números de telefone.

No início dos anos 1970, época em que o recém-cunhado termo "ensino a distância" estava relacionado principalmente a cursos por correspondência e ninguém sequer cogitava a popularização da internet que ocorreria no final do século, o pesquisador Michael G. Moore publica artigos que, futuramente, ajudariam a compor a chamada "Teoria da Distância Transacional" (BOYD; APPS, 1980; MOORE, 1993, 2013). Segundo o autor, a distância transacional é composta por três dimensões: "estrutura", relacionada ao currículo dos cursos e sua rigidez/flexibilidade; "diálogo", que envolve a comunicação entre aluno e professor; e "autonomia", que "descreve o papel dos alunos na decisão do que, como e quanto aprender"10 (MOORE, 2013, p. 68, tradução nossa). O britânico também reforça a importância de adotar o termo "diálogo" em lugar de "interação", uma vez que considera que o primeiro representa perfeitamente o fator positivo necessário para o bom andamento do processo de ensino e aprendizagem e que uma interação per se também pode ser negativa ou neutra (MOORE, 1993).

Com relação à sua constituição, a distância transacional seria uma função das duas primeiras dimensões (i.e., quanto maior a estrutura e menor o diálogo, maior será a distância transacional entre o estudante e o instrutor/professor), enquanto a terceira estaria relacionada à própria distância — quanto maior a distância, maior a autonomia exigida por parte do aluno (MOORE, 2013).

Segundo Dotta (2014), a proximidade transacional em excesso, exemplificada pelo vínculo de dependência docente-aluno, pode impedir o estabelecimento da terceira variante, a autonomia. A Teoria da Distância Transacional indica que alunos autônomos são aqueles capazes de decidir sobre seu estudo por iniciativa própria. Como apontado por Peters (2001), os alunos tornam-se autônomos quando assumem e "reconhecem

\footnotetext{
10 "The third described the roles of learners, in terms of the extent to which they exercise degrees of 'autonomy'in deciding what to learn, how to learn, and how much to learn."(MOORE, 2013, p. 68). 
suas necessidades de estudo, formulam seus objetivos, selecionam conteúdos, buscam materiais e constroem formas de aprendizagem de acordo com seus interesses, condições e significado" (PETERS, 2001, p. 55). Essa autonomia, portanto, "vai se constituindo na experiência de várias, inúmeras decisões, que vão sendo tomadas [...] é processo, é vir a ser, não ocorre em data marcada" (FREIRE, 1996, s. p.).

Oliveira et al. (2007) sustentam, por exemplo, "que a Internet, utilizada como ambiente de aprendizagem, pode criar um espaço flexível e colaborativo, muito adequado à construção do conhecimento de forma autônoma e significativa” (p. 1419). Embora estejamos de acordo com as autoras, acreditamos que o oposto também é verdadeiro, isto é, que o espaço virtual possa criar a dependência do professor, o que impede o desenvolvimento da autonomia do alunado - algo que pudemos observar em nossa experiência com o ERE, como explicaremos a seguir.

\section{ABRINDO JANELAS NAS MEDIANERAS: DIÁLOGO E RELAÇÕES SO- CIAIS DURANTE O ISOLAMENTO}

Em Medianeras (2011), um momento-chave é quando os protagonistas estão abrindo janelas ilegais nas paredes de seus apartamentos mal iluminados. Moura (2016, p. 86) apresenta uma excelente definição do que representa esse momento para Mariana e Martín:

$\mathrm{O}$ ato de abrir uma janela na medianera aparece como uma metáfora de esperança, como um ponto de fuga de uma realidade existente. Abrir uma janela na medianera representa abrir uma janela para o mundo, representa também a possibilidade de se abrir para a cidade e para novas relações. A contravenção de abrir a medianera se transforma na esperança de abrir uma nova possibilidade de comunicação, nesse caso, de comunicação com o urbano.

Em nosso caso, essa comunicação não é com o urbano, mas com o ser humano. A comunicação apenas com a máquina e com os aplicativos de difícil instalação e uso faz com que os alunos percam a motivação para o ensino. Ao "abrirem a janela" que possibilita a interação com os professores, surge uma nova possibilidade de comunicação e a esperança de que o aprendizado vai acontecer apesar da pandemia e/ou do ensino remoto. Por isso, o maior desafio enfrentado nesse período foi justamente descobrir como interagir com os alunos e proporcionar a todos um ambiente de ensino sustentável, que permitisse que eles alcançassem seu objetivo principal (aprender um pouco mais sobre a língua espanhola e ser aprovados no exame de suficiência) sem que houvesse Revista X, v. 16, n. 4, p. 1101-1119, 2021. 
um esgotamento mental e emocional dos envolvidos. Ambos, professores e alunos, aprendemos, durante esse processo, como tornar as aulas mais acessíveis e interessantes, em uma aprendizagem simultânea.

Esses obstáculos surgiram de diversas maneiras, primeiramente evidenciados em toda a discussão e questionamentos que apareceram acerca do ERE, sua relevância e adequação no ambiente educativo, e, posteriormente, em um sentido muito mais específico, nas estratégias que poderíamos adotar para possibilitar a interação dos alunos. Diante do cenário desafiador, os primeiros a serem impactados nesse processo foram os professores, que tiveram que migrar abruptamente para o ambiente virtual de ensino com quase nenhum tutorial de sobrevivência ou dicas rápidas que pudessem facilitar nosso trabalho. Claro que os alunos também foram confrontados pela nova maneira imposta de aprender, mas o que nos parece mais interessante no momento, e que faz parte do nosso processo de reflexão didática, é apresentar essa experiência do ponto de vista dos praticantes, demonstrando a teoria walloniana de um processo em que todos os agentes envolvidos são afetados.

O principal resultado de nossa tentativa de inserir os princípios defendidos por Wallon e aqueles que nele se baseiam foi a satisfação manifestada pelos alunos que terminaram o CE-M1/2020 tanto com as aulas como com a atenção dispensada pelos professores. Um exemplo de feedbacks que obtivemos nesse sentido está transcrito a seguir:

\begin{abstract}
A1: Car@s professores. Quero muito agradecer a vocês pelo curso de espanhol oferecido esse semestre. Estou apaixonada pela língua espanhola. Encontrei algo com que me identifico profundamente. Vou seguir estudando espanhol graças às aulas (as primeiras da minha vida) e ao carinho de vocês. Gratidão pelo empenho, incentivo e metodologia construída para o nosso grupo. Dividindo uma alegria com vcs! Chegou agora a resultado na prova de suficiência na PUCPR que fiz semana passada. Passei com nota 10. 0 Fruto dessa caminhada coletiva e tão rica nas aulas com os colegas e vcs. Que venham mais cursos!!! (WhatsApp, 30 jul. 2020).
\end{abstract}

A1 surpreendeu a todos ao enviar um feedback tão emotivo à equipe. A aluna sempre foi extremamente disciplinada e participativa, mas nos surpreendeu sobre o quão satisfeita ela se sentia com o nosso desempenho à frente do CE-M1/2020, uma vez que não sabíamos sua opinião sobre nós devido a um incidente ocorrido na segunda semana de curso, no qual ela enviou mensagens ao grupo de WhatsApp da turma solicitando de maneira enfática que solucionássemos o problema de uma colega. A questão era que essa 
aluna não conseguia cancelar a matrícula no curso, o que só poderia ser feito por ela mesma através do Sistema Integrado de Gestão Acadêmica (SIGA), um portal em que o aluno consegue acompanhar as disciplinas nas quais está matriculado e obtém acesso a documentos referentes à sua formação acadêmica. Por isso, ela enviou várias mensagens no Google Classroom com título: "SOCORRO”.

Com muitos pontos de exclamação, as mensagens enviadas por A1 representam o quanto ela estava incomodada com o recebimento dos muitos e-mails enviados pela colega. Mesmo tendo sido respondida imediatamente pela coordenadora do CE-M1/2020 no grupo de Whatsapp, A1 continuou insistindo para que o problema fosse solucionado, indicando que, talvez, tanto ela como a autora dos e-mails cogitassem a possibilidade de a situação estar sendo ignorada. No entanto, o problema era que a aluna aparentemente escrevia para um e-mail fantasia criado por alguma das plataformas ao qual nem os praticantes e nem a coordenação da pós tinham acesso, de modo que suas mensagens eram recebidas apenas pelos outros aprendizes.

Como não tínhamos acesso às matrículas, a ação realizada foi conversar com a coordenação pedindo instruções sobre como proceder e repassando as informações obtidas para seus colegas, uma vez que não tínhamos seu contato. Além disso, a coordenação do Programa de Pós-Graduação em Educação (PPGE) se disponibilizou a contatá-la para auxiliá-la no processo ${ }^{11}$. Acreditamos que, ao notar o quanto nos preocupamos pela situação da aluna assim que fomos informados, A1 percebeu nosso interesse sincero em fazer dessa uma experiência menos estressante para todos, se satisfazendo assim com nossas ações.

Outro ocorrido durante a última aula também demonstra como o nível de diálogo impactou positivamente a experiência de outra discente no CE-M1/2020. Uma aluna, que ingressou no curso como convidada pela coordenadora, nos deu o seguinte feedback durante a última aula:

A2: Como vocês sabem eu tô aqui na Espanha [...] A gente tinha feito aulas... aqui tem aulas da prefeitura, de espanhol [...] e eu achei a didática de vocês muito melhor do que a do curso. Eu aprendi muito mais com vocês do que eu aprendi em... um mês que eu fiz na escola aqui da Espanha mesmo. Então... era uma escola da prefeitura, pra estrangeiros e tudo mais, mas... ah... eu acho que a metodologia de

\footnotetext{
${ }^{11}$ Apesar das ações conjuntas, descobrimos, alguns dias depois e através de outra aluna, que a moça ainda enviava e-mails diariamente - por vezes mais de um por dia. Essa aluna nos informou que respondeu o e-mail solicitando que ela procurasse diretamente a coordenação do PPG responsável, uma vez que as pessoas que recebiam seus e-mails em nada poderiam ajudá-la (N. A.).
} 
vocês, a cultura, a forma como vocês aplicaram tudo foi muuuito legal e eu achei sensacional, todas as aulas... foi muito legal mesmo. Vocês tão de parabéns. (Transcrição de trecho de aula no Teams, 23 jul. 2020).

Ao reconhecer a diferença entre as metodologias adotadas por nós e pelos professores espanhóis com os quais teve contato quando iniciou o estudo da língua, essa aluna indica o bom funcionamento de uma abordagem pautada na afetividade para o ensino e aprendizagem de alunos brasileiros. Além disso, acreditamos também que a questão cultural influenciou nessa maior afinidade com o nosso curso, dado que, mais de uma vez, colegas e professores espanhóis comentaram sobre como a postura esperada de um professor no país ibérico é mais formal do que aquela com a qual se depararam no Brasil.

Nesse mesmo dia, recebemos também um feedback positivo de uma de suas colegas, dessa vez relacionado à questão do diálogo e sua influência positiva na criação de laços entre o grupo de regentes e os alunos:

\begin{abstract}
A3: Eu quero agradecer muito vocês... vocês são maravilhosas, vocês duas e todos os outros profes também... [...] todas as vezes que eu:: tentei participar vocês foram super acolhedoras... algumas vezes eu reclamei das minhas notas e vocês foram assim... super gentis... muito:.... extremamente inteligentes e têm uma desenvoltura, um jogo de cintura assim... pra lidar com a gente que... pra lidar com adulto não é fácil, né... e ainda com esse desafio desse ensino a distância... aprendendo as duas coisas ao mesmo tempo, a dar aulas e a::... a lidar com a tecnologia. Então eu só tenho a agradecer profundamente pelos ensinamentos, que eu morria de medo de espanhol ... inglês, assim, apesar de ser bem diferente do português eu tenho mais familiaridade... agora o espanhol eu MORRIA de medo e vocês fizeram com que:: eu não tivesse mais medo do espanhol, inclusive de falar em portunhol mesmo né... então eu só tenho a agradecer todos vocês, à professora Fernanda ${ }^{12}$, professora de vocês e a toda... todo esse grupo MARAVILHOSO que vocês são, de verdade. Obrigada por tudo! (Transcrição de trecho de aula no Teams, 23 jul. 2020).
\end{abstract}

No trecho, a referida aluna relembra um diálogo ocorrido pelo Google Classroom entre ela e uma das duplas de regentes. Ao receber a nota de um dos textos avaliativos do CE-M1/2020, A3 questionou as penalidades que foram realizadas pelas corretoras. Por isso, elas enviaram, no mesmo dia, um e-mail detalhando quais foram os descontos e a

\footnotetext{
${ }^{12}$ Não vimos razão para ocultar essa parte, uma vez que a professora mencionada é uma das autoras desse artigo (N. A.).
} 
razão de cada um deles. Por sua resposta, A3 pareceu compreender os fatores que fizeram com que seu texto não recebesse nota integral. $\mathrm{O}$ vínculo de afetividade proximal nas interações professor e aluno pareceu mostrar-se estabelecido quando a aluna agradeceu o retorno das professoras, bem como seu zelo em explicar, de maneira respeitosa e detalhada, todos os desvios cometidos por ela. A opinião de A3 não é isolada, dado que todos que responderam ao questionário enviado foram unânimes ao responder "sim" para todas as perguntas relacionadas à avaliação dos professores praticantes ${ }^{13}$.

No entanto, percebemos que nossa busca por um diálogo constante com o grupo trouxe um efeito colateral não imaginado previamente: alunos que pareciam possuir um perfil menos autônomo (ao menos no contexto virtual) passaram a ter algumas atitudes que indicavam um maior nível de dependência com relação aos professores no que dizia respeito a cobranças.

A situação a seguir exemplifica o que aconteceu na segunda aula da sexta semana. Em um dado momento, a professora pediu que alguns alunos lessem a letra da canção que haviam acabado de ouvir — que se encontrava tanto na UT (compartilhada no Google Classroom quatro dias antes) quanto na tela, que estava sendo compartilhada pela companheira da regente do dia.

P4: ((Nome do aluno)) Você está aí?

A4: Sim, profe... estou aqui

P4: Muito bem... Você pode ler para gente então ali, na segunda estrofe?

A4: Sim... "Entras en mi casa, tienes miedo a lo que soy..."

P4: É na primeira aqui... a que está ali... "Si sabes que voy..." É que profe ((nome da companheira)), baixou um pouquinho...

A4: Ah:::: Eu não tenho este arquivo... então estou...

P4: Ah:: não?

A4: ... estou vendo por sua tela

P4: Ah... então vou te enviar por WhatsApp...

A4: Estava tentando procurar no Google Classroom... mas não... não estou encontrando

\footnotetext{
${ }^{13}$ Ao final do curso, foi enviado aos alunos um questionário de avaliação do curso e dos praticantes aos alunos desse bloco (N. A.).
} 
P4: Não tem problema... vou te enviar... (Transcrição de trecho de aula no Teams, 9 jul. 2020) $)^{14}$

No excerto apresentado, vemos que, apesar de ser a segunda aula da semana, um dos alunos diz não ter tido acesso à UT que foi disponibilizada em PDF à turma no início da semana, apenas informando a questão quando a professora the pede que leia a canção. P4, ao se dar conta disso, automaticamente envia o arquivo por WhatsApp a esse aluno. A linguagem utilizada por ela no momento da resposta é diversificada e composta por uma fala informal, o que propicia uma maior aproximação entre os participantes. É importante salientar que a estratégia de utilizar uma abordagem mais informal nas aulas foi adotada pela maioria dos professores-em-formação como forma não apenas de favorecer o diálogo entre alunos e professores, mas também para deixá-los mais confortáveis com a língua estrangeira com a qual muitos deles têm contato por séries televisivas às quais assistem.

Com relação à autonomia, é interessante perceber que, sete dias depois, esse aluno comunica o mesmo problema, também na segunda aula da semana e também quando o professor responsável solicita que ele faça uma atividade do material. Se, no primeiro caso, a falta de material poderia ser justificada pelo fato de o aluno não ter participado da primeira aula, isso não ocorreu dessa vez, já que o aluno havia participado de ambas as aulas. Além disso, o material citado havia sido compartilhado duas vezes no grupo de WhatsApp - uma por uma das regentes da semana e outra por uma das alunas da turma, a pedido de um terceiro companheiro - indicando um padrão do aluno de apenas informar problemas ao buscar o material quando diretamente solicitado a realizar atividades.

A partir de todas as bibliografias consultadas e da prática docente por nós realizada, é possível apresentar um panorama geral do que observamos com relação às

\footnotetext{
${ }^{14}$ Tradução da interação original: P4: ((Nome do aluno)) ¿tú estás ahí? A4: Sí profe... estoy aquí

P4: Muy bien... ¿Tú puedes leer para nosotros entonces allí, en la segunda estrofa?

A4: Sí... "Entras en mi casa, tienes miedo a lo que soy..."

P4: Es la primera aquí... la que está allí... "Si sabes que voy..." es que profe ((nome da companheira)), bajó un poquito...

A4: Ah::.: Yo no tengo este arquivo (sic)... entonces estoy...

P4: Ah:: ¿no?

A4: ... estoy viendo por su tela ( sic)

P4: Ah... entonces voy a enviarlo para ti por WhatsApp...

A4: Estaba tentando ( $\mathrm{sic}$ ) procurarlo en Google Clase... pero no... no tengo encontrado ( $\mathrm{sic}$ )

P4: No pasa nada... voy a enviarte... (Transcrição de trecho de aula no Teams, 9 jul. 2020).
}

Revista X, v. 16, n. 4, p. 1101-1119, 2021. 
aulas do CE-M1/2020 na modalidade de ERE, oferecidas aos alunos de pós-graduação da UFPR no primeiro semestre de 2020. Primeiramente, como já mencionado no início deste artigo, percebeu-se um grande interesse do próprio PPG, que nos solicitou que ofertássemos o CE-M1/2020 para alunos da pós que precisavam realizar o exame de suficiência em língua estrangeira da UFPR. Dessa forma, unimos nossas necessidades às deles e, através do FIVU, pudemos realizar esse trabalho.

Por conta desse interesse ter partido da coordenação e dos próprios pósgraduandos, pensávamos que conseguiríamos estabelecer uma comunicação mais eficaz com os alunos. A semana que antecedeu o início do curso de Espanhol nos surpreendeu, porque tivemos que abrir outra turma para poder ofertar o curso para os mais de 30 alunos que se interessaram. Além disso, todos responderam ao questionário-diagnóstico elaborado a fim de avaliar como seria estruturado o curso, expressando seu interesse enfático em participar do projeto.

De acordo com Sousa (2006), é também esperado que no ambiente virtual tenhamos alunos autodidatas com mais controle na sua aprendizagem, mais participativos, flexíveis e comunicativos, reduzindo, assim, a distância transacional entre os alunos e o professor. Entretanto a interatividade entre nós e alguns alunos era exaustiva, já que muitas vezes era necessário insistir para obter um feedback dos alunos no momento da aula, quando lhes fazíamos perguntas relacionadas à temática trabalhada. Além disso, alguns quase não acessavam o Google Classroom (apenas para enviar as tarefas) e, por isso, o material das aulas que disponibilizávamos nessa plataforma precisava ser reenviado via WhatsApp (às vezes mais de uma vez) para que todos o abrissem, como pudemos perceber em exemplos anteriores. Algo parecido ocorria com relação ao Microsoft Teams, uma vez que, em ambas as turmas, precisávamos postar o link dos canais em que as aulas ocorriam ${ }^{15}$ todos os dias nos grupos de WhatsApp, ainda que o único dia em que eles tinham aula em um canal diferente era às sextas, quando juntávamos os dois grupos em um terceiro canal.

Entretanto nossa comunicação antes das aulas funcionava muito bem via WhatsApp. Sobre essa questão, podemos recorrer a Bacich, Tanzi Neto e Trevisani (2015, p. 14):

Nas etapas de formação, os alunos precisam do acompanhamento de profissionais mais experientes para ajudá-los a tornar conscientes alguns processos, a estabelecer conexões não percebidas, a superar etapas mais rapidamente, a confrontá-los com novas possibilidades.

\footnotetext{
${ }^{15}$ Cada turma tinha um canal próprio para suas aulas, uma vez que pensamos que alguns alunos poderiam se confundir com as datas se mantivéssemos um único canal para todos (N. A.). 
O interessante sobre isso é que tivemos que aprender junto aos nossos alunos, então não era um ambiente onde necessariamente havia alguém experiente. Na verdade, foi um processo mútuo e simultâneo de alfabetização tecnológica. Talvez o fato de termos usado muitos canais de comunicação (WhatsApp, Microsoft Teams e Google Classroom) tenha causado um certo esgotamento técnico, afinal, todos queremos praticidade em nossas comunicações. E o fato de não estarmos - tanto alunos como professores habituados com essas ferramentas, às vezes gerava algum desgaste. Inclusive, em uma das aulas cujo tema era Tecnología, internet y sociedad, foi realizada uma atividade introdutória na qual solicitamos que os alunos respondessem em três palavras o que para eles significava tecnologia. Algumas respostas apontaram a palavra "estresse".

Todos estávamos passando por um processo de adaptação, e claro que, em alguns momentos, o estresse por cair a conexão, travar a tela, não carregar o arquivo, falhar o som e outros imprevistos aconteceu. Entretanto, se comparamos o ambiente virtual e o físico, dentro da sala de aula, estamos livres desses incidentes? Definitivamente não. O que acontece é que nos acostumamos a contornar os desafios que surgem nas aulas presenciais. Para que também possamos nos adaptar aos desafios virtuais, Bacich, Tanzi Neto e Trevisani (2015, p. 23) sugerem uma "mudança de mentalidade", mudança essa que precisa ser guiada pela quebra de paradigmas e tradicionalismos, que podem nos afetar negativamente e nos impedir de avançar no desafio de abertura de janelas nas medianeras.

\section{"ENSINANDO A ENCONTRAR O WALLY NA CIDADE": O QUE APREN- DEMOS E COMO ISSO PODE AJUDAR OS PRÓXIMOS PROFESSORES- -EM-FORMAÇÃO?}

Em uma das cenas finais de Medianeras (2011), Mariana, que passou anos buscando Wally ${ }^{16}$ na imagem "Wally na cidade", finalmente o encontra: Martín, vestido como o personagem, passeia com seu cachorro sob a janela de Mariana, motivando-a a sair de seu apartamento e até a enfrentar seu medo de elevadores para alcançar seu objetivo. Da mesma forma, esperamos que esse artigo sirva como "janela" para que os próximos professores-em-formação possam "encontrar Wally", isto é, otimizar o planejamento e a execução dos cursos de idiomas virtuais que se seguirão ao nosso e, assim, obter resultados cada vez mais positivos e que permitam acabar com a ideia de

\footnotetext{
${ }^{16}$ Personagem da série Onde está Wally?, do ilustrador britânico Martin Handford, na qual a pessoa que está vendo as imagens deve buscar o personagem no meio de multidões em distintos ambientes (N. A.). 
que "o ensino virtual é de baixa qualidade" — visão apontada como "preconceituosa" por Hodges et al. (2020).

Para refletir sobre como aperfeiçoar esse ambiente virtual de aula, é válido considerar a seguinte proposição de Bacich, Tanzi Neto e Trevisani (2015, p. 14):

As metodologias precisam acompanhar os objetivos pretendidos. Se queremos que os alunos sejam proativos, precisamos adotar metodologias nas quais eles se envolvam em atividades cada vez mais complexas, em que tenham de tomar decisões e avaliar os resultados, com apoio de materiais relevantes. Se queremos que sejam criativos, eles precisam experimentar inúmeras novas possibilidades de mostrar sua iniciativa.

Sendo assim, se primeiramente considerarmos nosso papel como professores e a importância de selecionar e estudar diferentes metodologias que funcionem para esse determinado ambiente de aula, poderemos, além de atingir nosso objetivo inicial (que é a interatividade), possibilitar que os alunos descubram e construam sua própria maneira de interagir e aprender, já que o objetivo final e o foco de uma aula devem sempre ser o aprendizado do alunado.

Outro ponto de reflexão está relacionado ao que propõe a Teoria da Distância Transacional, segundo a qual a autonomia do aprendiz está relacionada à estrutura do curso ou disciplina em que está matriculado e da possibilidade de diálogo com seu professor (MOORE, 2013). Assim, é possível refletir se a pouca autonomia apresentada por alguns alunos do CE-M1/2020 oferecido pelo FIVU nos meses de junho e julho de 2020 não está relacionada ao fato de que os alunos dispunham de muitos canais de comunicação para entrar em contato com os professores, de modo que sentiram que podiam escolher quais utilizar e quais ignorar. Por isso, é importante para os futuros regentes pensar em como manter um canal de diálogo constante com os alunos sem que isso incorra em uma maior dependência na relação aluno-professor.

Assim, é possível inferir que a educação remota precisa sempre incentivar o afetivo por meio da comunicação, pois, como bem diz Moran (2004, p. 1):

O afetivo dinamiza as interações, as trocas, a busca, os resultados. Facilita a comunicação, toca os participantes, promove a união. $\mathrm{O}$ clima afetivo prende totalmente, envolve plenamente, multiplica as potencialidades. O homem contemporâneo, pela relação tão forte com os meios de comunicação e pela solidão da cidade grande, é muito sensível às formas de comunicação que enfatizam os apelos emocionais e afetivos mais do que os racionais. 


\section{REFERÊNCIAS}

BACICH, L.; TANZI NETO, A.; TREVISANI, F. M. Ensino híbrido: personalização e tecnologia na educação. Porto Alegre: Penso, 2015.

BARRA, E.; GOMES, J. A universidade se faz presente. Plural, Curitiba, 23 jun. 2020. Disponível em: https://www.plural.jor.br/artigos/a-universidade-que-se-faz-presente/. Acesso em: 23 jun. 2020.

BOYD, R.; APPS, J. Redefining the Discipline of Adult Education. San Francisco: Jossey-Bass, 1980.

BOZKURT, A.; SHARMA, R. C. Emergency remote teaching in a time of global crisis due to CoronaVirus pandemic. Asian Journal of Distance Education. v. 15, n. 1, 2020, p. 1-6. Disponível em: https://www.researchgate.net/publication/341043562_Emergency_ remote_teaching_in_a_time_of_global_crisis_due_to_CoronaVirus_pandemic. Acesso em: 3 maio 2021.

DOTTA, S. (org.). Aulas virtuais síncronas: Condução de webconferência multimodal e multimídia em Educação a Distância. Santo André: Universidade Federal do ABC, 2014.

FERREIRA, A. L.; ACIOLY-REGNIER, N. M. Contribuições de Henri Wallon à relação cognição e afetividade na educação. Educar em Revista. Curitiba, n. 36, 2010, p. 2138. Disponível em: https://revistas.ufpr.br/educar/article/view/17577. Acesso em: 3 maio 2021.

FREIRE, P. Pedagogia da autonomia: Saberes necessários à prática educativa. 7. ed. São Paulo: Paz e Terra, 1996.

FREIRE, P. Pedagogia do Oprimido. 42. ed. Rio de Janeiro: Paz e Terra, 2005.

HODGES, C.; MOORE, S.; LOCKEE, B.; TRUST, T.; BOND, A. The difference between emergency remote teaching and online learning. EDUCAUSE Review. 27 mar. 2020. Disponível em: https:/er.educause.edu/articles/2020/3/the-difference-betweenemergency-remote-teaching-and-online-learning. Acesso em: 3 jun. 2020.

MAHONEY, A. A.; ALMEIDA, L. R. de. Afetividade e processo ensino-aprendizagem: contribuições de Henri Wallon. Psicologia da Educação. São Paulo, n. 20, 1. sem. 2005. p. 11-30. Disponível em: https://revistas.pucsp.br/psicoeduca/article/view/ 43324/28804. Acesso em: 7 jul. 2020.

MEDIANERAS. Direção: Gustavo Taretto. Produção: Natacha Cervi \& Hernán Musaluppi. Buenos Aires: Aura Films, 2011. 
MOORE, M. G. The Theory of Transactional Distance. In: MOORE, M. G. (ed.). Handbook of Distance Education. 3. ed. London and New York: Routledge, 2013, p. 66-85.

MOORE, M. G. Theory of transactional distance. In: KEEGAN, D. (ed.). Theoretical Principles of Distance Education. London and New York: Routledge, 1993, p. 22-38.

MORAN, J. M. A educação que desejamos: novos desafios e como chegar lá. Campinas: Papirus, 2004.

MORAN, J. M. Ensino e aprendizagem inovadores com tecnologias audiovisuais e telemáticas. In: MORAN, J. M.; MASETTO, M. T.; BEHRENS, M. A. Novas tecnologias e mediação pedagógica. 5 ed. Campinas: Papirus, 2000, p. 11-66.

MOURA, V. P. T. Espaços urbanos e relações contemporâneas no filme Medianeras. 2016. 105 f. Dissertação (Mestrado em Estudos da Mídia) — Programa de Pós-Graduação em Estudos da Mídia, Universidade Federal do Rio Grande do Norte, Natal, 2016.

OLIVEIRA, E. S. G. de; REGO, M. C. L. C.; VILLARDI, R. M. Aprendizagem mediada por ferramentas de interação: análise do discurso de professores em um curso de formação continuada a distância. Educ. Soc., Campinas, v. 28, n. 101, dez. 2007, p. 14131434. Disponível em: http://www.scielo.br/scielo.php?script=sci_arttext\&pid=S0101$73302007000400008 \& \operatorname{lng}=$ en\&nrm=iso. Acesso em: 3 ago. 2020.

PETERS, O. Didática do ensino a distância. Experiências e estágio da discussão numa visão internacional. Tradução Ilson Kayser. São Leopoldo: Unisinos, 2001.

SOUSA, S. Confio em ambientes virtuais de aprendizagem. 2006. Laboratório de Educação Digital, Universidade Jean Piaget de Cabo Verde. Disponível em: https://www. academia.edu/2742341/Confio_em_ambientes_virtuais_de_aprendizagem. Acesso em: 25 jul. 2020.

WALLON, H. Psicologia e educação da infância. Lisboa: Estampa, 1975.

Recebido em: 11 ago. 2020.

Aceito em: 07 out. 2020. 